\title{
Coping strategy of women with HIV-AIDS: Influence of Care-giving, family social attitude, and effective communication
}

\author{
Regina Udobong ${ }^{1}$, Ndifreke Udonwa ${ }^{2}$, Okon Charles ${ }^{3}$, Promise Adat ${ }^{2}$, Rose Udonwa ${ }^{4}$ \\ ${ }^{1}$ Department of Nursing Services, University of Calabar Teaching Hospital, Calabar, Nigeria \\ ${ }^{2}$ Department of Family Medicine, University of Calabar, Calabar, Nigeria \\ ${ }^{3}$ Department of Sociology, University of Calabar, Calabar, Nigeria \\ ${ }^{4}$ Department of Vocational Education, University of Calabar, Calabar, Nigeria

\section{Email Address:} \\ rudobong@gmail.com (R. Udobong),nudonwa@yahoo.com (N. Udonwa), ojcharles@yahoo.com (O. Charles), \\ promiseadat@yahoo.com (P. Adat), rudonwa@yahoo.com (R. Udonwa)
}

\section{To cite this article:}

Regina Udobong, Ndifreke Udonwa, Okon Charles, Promise Adat, Rose Udonwa. Coping Strategy of Women with HIV-AIDS: Influence of Care-Giving, Family Social Attitude, and Effective Communication. Science Journal of Public Health. Vol. 3, No. 1, 2015 , pp. $107-113$. doi: $10.11648 /$ j.sjph.20150301.29

\begin{abstract}
This study investigated the relationship between family support and coping strategy of women living with HIV/AIDS in the outpatients and the Heart to Heart Units of University of Calabar Teaching Hospital, Calabar. A 24-item questionnaire was administered to female health care providers. Also Focus Group Discussion (FGD) and In-depth Interview / Key Informant Interview was held among 160 randomly selected respondents. The generated data were analysed using the SPSS package. The analyses revealed that significant relationship exists between care giving, favourable social attitude, and effective communication (exposure to information) and coping strategy of women living with HIV/AIDS. The authors recommend that the family should show itself as the most fundamental institution for the successful management of HIV/AIDS; and conclude that the family should develop favourable social attitude, provide proper and good care and sufficiently expose women living with HIV/AIDS to appropriate information.
\end{abstract}

Keywords: Coping Strategy, Care-Giving, Family Support, Communication

\section{Introduction}

HIV is rapidly spreading in sub-Saharan Africa, affecting youth and adults at a frightening pace. The region is home to about 10 percent of the world's population, but has more than 60 percent of all people living with $\mathrm{HIV}^{[1]}$. The number of women with Human Immuno-deficiency Virus (HIV) infection and Acquired Immuno-Deficiency Syndrome (AIDS) has increased steadily worldwide ${ }^{[2]}$ and Nigeria is no exception ${ }^{[3]}$. Reports indicate that by the end of year 2012, 35 million women worldwide were living with HIV/AIDS ${ }^{[4],[5]}$.

As at December 2012, women accounted for nearly half of all adults living with HIV worldwide and about $60 \%$ in SubSahara Africa ${ }^{[6]}$. In 2012, 57\% of people living with HIV in Sub Sahara Africa were women. At the end of 2012, it was estimated that $52 \%$ of people living with HIV and Aids in low and middle income countries are women ${ }^{[7]}$
There are 13 women living with HIV for every 10 infected men ${ }^{[8] .}$ Many of them are being infected despite staying loyal to one partner. Social conventions and cultural traditions tend to subordinate women and they have little authority in their sexual relationships. ${ }^{[9]}$

Women are twice more likely to acquire HIV from men during sexual intercourse. Reports from Sub Sahara Africa, indicate that women constitute $58 \%$ of all people living with HIV. In 2013 about $60 \%$ of all new HIV infection among young people aged 15-24 occurred among adolescent girls and young women. ${ }^{[6]}$

Women are particularly susceptible to HIV due to a complex combination of factors-ranging from the biology of the virus, to the anatomy of the female genital tract, to socio cultural traditions. Women's low socio-economic status 
marked by low income levels, poverty, limited education and subordination, especially in sexual decision making exposes them to a greater risk of HIV infections ${ }^{[10,11]}$. For instance traditional practices such as polygyny increases women's susceptibility to HIV. As elsewhere, poverty forces many young women to seek work with older men, to pay for their education, clothing and other basic needs ${ }^{[12]}$. Even, children orphaned by HIV parents resort to prostitution as the only means of supporting themselves and their younger siblings ${ }^{[13]}$.Orphans are likely to be exposed to risk behaviour via a number of mechanisms. Firstly due to the death of their parents and losing their source of livelihood they may be engaged in transactional sex which is often used by some women to cope with unexpected health shocks, including the illness or even death of another household member. ${ }^{[14]}$. Again sexual violence, experienced by some women increases the risk of HIV due to abrasions caused by forced vaginal or anal penetration ${ }^{[15,16]}$.

A woman with HIV infection often is a member of an infected family; one or more of her children, may have been infected vertically; she is often the primary caregiver for other sick family members, despite her own illness ${ }^{[17]}$. The burden of caring for AIDS orphans usually falls on women, creating extra demands on their time and resources, especially in poor families ${ }^{[11]}$. Likewise condemnation, discrimination and stigmatization are issues for women living with HIV/AIDS to deal with. Some are supported by the family while others are likely to be treated like outcast irrespective of the source of the infection ${ }^{[18]}$

In the same line, Schatz, Mudha and William in 2011 observed that female heads of households, in particular, do not own or have direct access to the necessary finances to meet the family's health needs as expected of them ${ }^{[19]}$ As they take on the additional burden of caring for those with HIV/AIDS, their social and economy resources become inadequate. The poor economic background of women heightens their vulnerability to HIV/AIDS infection. Widowed and deserted women most times resort to sexual favours to survive. Biological factors during heterosexual encounter in women is greater than men because of the greater quantity of fluids, and the micro tears that can occur in vaginal or rectal tissue form sexual penetrations $[8,1]$. Furthermore women's vulnerability is increased by the presence of sexually transmitted infections, especially ulcerative ones such as syphilis and herpes. Most STIs are asymptomatic in women and the women may not realize they need treatments. This situation impedes early detection and timely treatment of STIs in women, thus increasing their chances of contracting HIV.

A cursory look at the Special Treatment Clinic in the University of Calabar Teaching Hospital (UCTH), Calabar, Nigeria shows treatment of one opportunistic infection or the other among women. These women are not just one homogenous group but range from poor or rich, young and old, educated or uneducated, low and high status, to antenatal and women with infertility problems. How these women cope living with HIV/AIDS can only be imagined. How supportive the families of these women are to increase their chances of surviving with the infection; how the actions of the family strengthen or weaken the strategy of women living with HIV/AIDS; how they are treated by the family members after the diagnosis; how favourable the social attitude are; the kind of care the families give to these women; how they are exposed to information that will help them cope are puzzles which if addressed may minimise the burden of HIV/AIDS on women.

This study attempted to examine women in relation to HIV/AIDS, and the supportive role of the family as they cope with the phenomenon. It investigated the relationship between family support and coping strategy of women living with HIV/AIDS, how much family support enhances coping strategy of women living with HIV/AIDS, whether favourable social attitude like care-giving and effective communication or exposure to information have any relationship between coping strategy and women living with HIV/AIDS. The data obtained from this study shall be of immense use to scholars, health care planners, researchers, policy makers, medical sociologists, and others interested in unraveling such information about family support and coping strategy of women living with HIV/AIDS.

\section{Methodology}

\subsection{Study Setting and Population}

This descriptive study focused on family support and coping strategy of women 19 years and above, both single and married, except pregnant women, living with HIV/AIDS in Calabar Municipality who visit the Special Treatment Centre (STC)of University of Calabar Teaching Hospital, Calabar (UCTH) for HIV/AIDS treatment between 20052007, and female health care providers. The UCTH, Calabar was established in 1979 following the need for a tertiary health institution that would render clinical services at a level to meet the health need of the state. St. Margaret's Hospital and Maternity Annex, established in 1897 were taken over by the Federal Government and became the teaching hospital in 1979. The Hospital like other teaching hospitals functions to development of manpower at undergraduate and postgraduate levels, offer clinical care at tertiary level, including comprehensive HIV/AIDS care and treatment, and research. Because of its geographical location, it serves not only Nigerians but other surrounding African Countries like the Republic of Cameroon and Equatorial Guinea.

The Special Treatment Centre was established in May, 2005 and provides counseling, clinical care and Antiretroviral drugs for treatment of patients living with HIV/AIDS. The centre is manned by Teaching Hospital staff within the Family Medicine Department of the Hospital.

\subsection{Study Sample}

Within the study period 1683 clients, 746 male and 937 women, received treatment at the centre. Out of the entire number of women living with HIV/AIDS, a sample of eight 
to twelve (8-12) women, per session were selected for Focus Group Discussion (FGD)/ In-depth interview (IDI) based on the identified family support variables and the coping strategy of the women living with HIV/AIDS. Key Informant Interview (KII) was also conducted. Records of women and men receiving treatment in UCTH Special Treatment Centre covering the period between 2005 and 2007 were also consulted.

Four sessions of FGD were conducted. The first group comprised of 8 participants while the other groups had 10 participants. The first session lasted for about 70 minutes with a break after 40 minutes and a brief recap made to participant by the moderator. The other sessions lasted for about 90 minutes with a mid-way break after 50 minutes. Participants at all the sessions of FGD were mixed, made up of a few married women mostly with HIV negative husbands, few single ladies with strong desire and hope of getting married and many windows. Their age bracket varied between 30 years and 40 years. Few were civil servants (worried about their job security). The rest were petit traders and unemployed. Their interactions expressed diverse opinions about their "New social status and life".

One hundred and sixty (160) Female Health Care Providers in the outpatients department of UCTH were interviewed also using a 24-item researcher-designed questionnaire. It consisted of two sections - A and B. The questionnaire aimed at eliciting information from female health care providers on family support variables. The items were based on existing literature on family support variables. Section A, contained items seeking information on the demographic characteristics of respondent such as sex, age, marital status, religion, educational attainment and unit of service. Section B consisted of 18 items measured on 4-point Likert scale that measured opinion of people about women living with HIV/AIDS and their coping strategies. The section was further divided into 3 sub-sections (sub-scale) that measured family support variables. (Sub scale B1= Social attitude, Sub scale B2 = care giving, Sub scale B3 = Effective communication (exposure to information).

Sampling technique used included purposive and stratified techniques. The content and face validity of the questionnaire were established by the researcher and appraised for content and face validity by the supervisor. To determine the reliability of the instrument, a trial testing was carried out by the researcher. This involved administering the instrument on thirty (30) randomly sampled respondents from the study area.

The instruments were administered on these 30 respondents who were not part of the respondents in the study. The instrument was also retrieved on the same day. The responses from the two instruments administered on the two sessions were separately prepared by coding and the codes were subjected to split-half reliability analysis. The analysis produced reliability estimates ranging from 0.921 to 0.984 .

The trial version of the questionnaire was administrated to 160 randomly selected health care practitioners in the outpatient department of UCTH. Also, the Focus Group
Discussion (FGD) and In-depth Interview together with Key Informant Interview were carried out with the help of some trained research assistants in the study unit. This was useful in avoiding non-return of questionnaire by the respondents. In order to get data for coping strategy, several visits were made to the Heart to Heart Centre where the study subjects were contacted personally, and responses were given on the spot.

The generated data was first subjected to preparation by scoring and coding of each retrieved questionnaire. First, each of the questionnaires was individually assigned a score or code based on the response option provided for each item. For example, in section A part of the instrument, the first item was categorized into two, male was assigned 1-point and female 2-points. The second item was age. It was categorized into:

Less than 25 (scored 1 point); 25-29 years (scored 2 points) 30-34 years (scored 3 points), 35 years and above, (scored 4 points). The third item was marital status. It was categorized into: single-scored 3 point, married -scored 2 points, widowed-scored 3 points and divorced-scored 4 points, widowed-scored 3 points. The next item was religion, it was categorized into Christian scored 1 point, Islam scored 2 points and traditional scored 3 points. The same was done for highest educational attainment.

In part B of the instrument, items were scored based on the 4 points Likert scale type beginning with all positively worded items: "SA' for" strongly Agreed" scored 4 points, "SD" for strongly Disagreed" scored 1 point. After scoring all the 160 scripts, codes were extracted and stored in a person by person matric table (data bank). It was from this table that the prepared data were extracted and used for statistical analysisusing Pearson Product moment analytical procedure of the SPSS package (CDC Atlanta, Georgia, USA).

\section{Results and Discussion}

\subsection{Descriptive Analysis Result}

A total of one hundred and sixty (160) questionnaires were administered and used for the analysis. All the respondents representing $100 \%$ of the total respondents were female.

Nine $(5.63 \%)$, were less than 25years old. Twenty three $(14.37 \%)$ were $25-29$ years, $50(31.25 \%)$ were between $30-34$ years while $78(31.25 \%)$ were between $30-34$ years while 78 (48.75\%) of a total respondents were 35 and above Table 1.

Table 1. Distribution of respondents by age, marital status, religion, highest education attainment and unit of service.

\begin{tabular}{ll}
\hline Parameter & Respondents $\mathbf{N}=\mathbf{1 6 0}$ \\
\hline Equally & as \\
Less than 25 & $9(5.6)$ \\
$25-29$ & $23(14.4)$ \\
$30-34$ & $50(31.3)$ \\
35 and above & $78(48.8)$ \\
Total & $160(100)$ \\
Unit of service & Respondents \\
OPD & $104(65)$ \\
\hline
\end{tabular}




\begin{tabular}{ll}
\hline Parameter & Respondents N=160 \\
\hline Casualty & $31(19.4)$ \\
Records & $25(15.6)$ \\
Laboratory & $0(0)$ \\
Total & $160(100)$ \\
Marital status & Respondents \\
Single & $32(20)$ \\
Married & $103(64.4)$ \\
Widowed & $14(8.8)$ \\
Divorced & $11(6.9)$ \\
Total & 160 \\
Religion & Respondents \\
Christianity & $160(100)$ \\
Islam & 0 \\
Traditional & 0 \\
Total & $160(100)$ \\
Highest Educational attainment & Respondents \\
Complete secondary school & $32(20)$ \\
Tertiary & $102(63.8)$ \\
Others & $26(16.2)$ \\
Total & $160(100)$ \\
\hline
\end{tabular}

The table also shows that, 32 respondents $(20 \%)$ were single, $103(64.37 \%)$ were married, 14 (8.75\%) were widowed while 11 respondents $(6.87 \%)$ were divorced.

All respondents i.e. $100 \%$ were Christians as there was neither Moslem nor traditional worshipper.

Likewise from the table, 32 respondents representing 20\% completed secondary school, 102 respondents representing $63.75 \%$, had tertiary education while 26 respondents representing $16.25 \%$ had other forms of educational attainment like, Ordinary National Diploma (OND) and others.

Table 2. Pearson Product Moment analysis of the relationship between favourable social attitude and coping strategy of women living with HIV/AIDS. $N=160$

\begin{tabular}{lllll}
\hline Variables & $\sum \mathbf{X}$ & $\sum \mathbf{X}^{2}$ & \multirow{2}{*}{$\sum \mathbf{X Y}$} & \multirow{2}{*}{$\mathbf{R}$-cal } \\
\cline { 2 - 4 } & $\sum \mathbf{y}$ & $\sum \mathbf{Y}^{\mathbf{2}}$ & & \\
\hline Favourable Social attitude & 2987 & 4756 & \multirow{2}{*}{89473} & 0.90 \\
Coping Strategy & 2611 & 4694 & & \\
\hline
\end{tabular}

Equally as shown in Table 1 the units of service of respondents were varied. One hundred and four (65\%), belonged to OPD, $31(19.37 \%)$ were in casualty while those in records were 25 representing $15.63 \%$. There was no respondent from the laboratory unit.

Table 2 shows that the positive nature of the correlation coefficient suggest that favourable social attitude of families is significantly associated with the coping strategy of women living with HIV/AIDS.

Significant at .05 level, $\mathrm{df}=158$ and critical $\mathrm{r}$-value $=$ 0.1964 .

Also there is significantly high relationship between care giving and coping strategy of women living with HIV/AIDS because the calculated r-value of 0.92 is greater than the critical r-value of 0.1964 at .05 level of significant with 158 degrees of freedom, Table 3.
Table 3. Pearson Product Moment analysis of the relationship between care giving and coping strategy of women living with HIV/IADS. N=160

\begin{tabular}{lllll}
\hline \multirow{2}{*}{ Variables } & $\sum \mathbf{X}$ & $\sum \mathbf{X} 2$ & \multirow{2}{*}{$\sum \mathbf{X Y}$} & R-cal \\
\cline { 2 - 3 } & $\sum \mathbf{y}$ & $\sum \mathbf{Y 2}$ & & \\
\hline Care Giving & 3019 & 4763 & & 0.92 \\
Coping Strategy & 2611 & 4694 & & \\
\hline
\end{tabular}

Significant at .05 level, $\mathrm{df}=158$ and critical $\mathrm{r}-$ value $=$ 0.1964

The evidence in table 4shows that the observed r-value of 0.87 is significantly greater than the critical r-value of 0.1864 at 0.05 level of significance with 158 degrees of freedom.

Table 4. Pearson Product moment analysis of the relationship between effective communication and coping strategy of women living with HIV/AIDS. N=160

\begin{tabular}{lllll}
\hline \multirow{2}{*}{ Variables } & $\sum \mathbf{X}$ & $\sum \mathbf{X}^{2}$ & \multirow{2}{*}{$\sum \mathbf{X Y}$} & \multirow{2}{*}{$\mathbf{R}$-cal } \\
\cline { 2 - 3 } & $\sum \mathbf{y}$ & $\sum \mathbf{Y}^{\mathbf{2}}$ & & \\
\hline Effective Communication & 2939 & 4655 & & \\
Coping Strategy & & & 85435 & 0.87 \\
\hline
\end{tabular}

Significant at .05 level, $\mathrm{df}=158$ and critical $\mathrm{r}$-value $=$ 0.1964 .

This implies that effective communication has a significant positive relationship with coping strategy of women living with HIV/AIDS.

\subsection{Discussion}

From the study, the relationship between favourable social attitude and coping strategy of women living with HIV/AIDS is established. So far, the opinions of women both of the FGDs, and IDI proved that they still hide their HIV status from family members because they do not receive favourable attitude from these persons. More frustrating and painful is the fact that these close relations who ought to provide immediate support and advice to them rather reject them, isolate them or pretend to sympathize with them. According to some respondents "by the time they hear that, abuses will come". "When my husband people knew, nobody helped me, even the house that my husband built for me they took it from me". "When I tested positive my brother's wife threw me out and they don't allow me to enter the house" "My father's people rejected me". "The public should not take us as people who cannot make it in life". The women interviewed wished that the society could accept them as they are in their new "status"; as superficial show of sympathy is not enough.

The findings are also consistent with the fact that that favourable social attitude is positively directed towards those living with HIV/AIDS and is expected to promote healthy living in the family. Favourable attitude influences the thought processes and predispositions of the family members to behave positively towards women living with HIV/AIDS. Families would not spend money on HIV positive mothers care. "Anyway they will die in future. It's better to use 
money properly" said one mother in-law. The findings also agrees that favourable social attitude ensures a comfortable and warm family relationship that if the family attitude is less favourable women living with HIV/AIDS will be subjected to fear of discrimination and can prevent them from seeking treatment for AIDS or joining support groups. [20],[21],[22]. Supportive extended family whether biological and traditional or chosen and community based can be influenced in aiding HIV positive people to lead a better quality of life. People living with HIV tend to live a better live when they have family support. [21]. The lack of favourable social attitude leads to feelings of abandonment and frustration by women living with HIV/AIDS.

The above findings were also consistent with the FGD thematic analysis. The discussants agreed that the reaction of family members is demonstrated in their social attitude. One of the discussants stated: "why I am afraid to go out to obtain Anti- Retroviral drug is because my family members have abandoned me to die and nobody supports me". In the IDI, one of those interviewed agreed that better social attitude by the family members can sustain women living with HIV/AIDS.

Our study supports the fact that failure to give needed help by the family due to negative attitudinal formation is devastating to women living with HIV/AIDS [22,23,24]. Therefore the family should provide succor to women living with HIV/AIDS as a mechanism for coping with the problem.

The respondents agreed that care giving was significant and even indispensable to women living with HIV/AIDS in order to help them cope. The qualitative data supported the quantitative analysis to show that women living with HIV/AIDS were not given enough care to enhance their coping strategies. According to one of the members in Living Hope Support Group, "the children know, they show love but sometimes they are frightened" as found out by Henrike Korner[25, 26] that disclosing to children was a difficult decision since some of their children responded positively while others had problematic disclosure because their children thought that their mothers acquired HIV because of being bad.

A respondent in IDI group stressed that "support is from mama and papa in the Lord, they provide food supplement". Another said "my brother is supportive but it is not enough; I wish that once a month or every two months the government should package something and attach to the drugs and also get employment for us". In accordance with this view, it is acknowledged that an Austrian Aid Organization, Caritas provided food and medical and educational assistance to children with AIDS orphans. [27,28]. An interviewee complained, "when my husband found that I was positive, he sent me away and started bringing women to the house". These behaviours do not depict care and respect that women living with HIV/AIDS expect from their immediate environment.

The findings also support the view that women with HIV/AIDS often lack access to appropriate medical care, encouragement and moral support from the family [29,30]. This stresses that family support for women living with HIV/AIDS include providing proper health, medical education and moral backup.

The findings are also consistent with the opinion that families are important care givers providing emotional and instrumental support for members with HIV [31]. This helps to buffer stress, improve adherence, reduce symptoms of depression, and fast tracts restoration of quality of live. Consequently such support will forestall a sense of shame, anxiety, guilt, discrimination and stigmatization that these women are often exposed or subjected to.

To further support the findings of this study, NYSC reproductive health and HIV/AIDS prevention project [32] concluded that care giving is a primary family support function. It stated that there are now so many HIV/AIDS patients in Nigeria that the hospitals and clinics cannot take care of them. Most hospitals now send women living with HIV/AIDS home for home-based care which is perceived as economically viable and preferred over hospital based care because it ensured confidentiality and patient care without hampering routine work at home [33]. This makes the responsibilities of taking care (by providing love/affection) of those living with HIV/AIDS a family affair.

The explanation for the existence of relationship between care giving and coping strategy of women living with HIV/AIDS is that since most of these victims are dying rapidly due to denial of moral support, it is necessary for the family to pay greater attention to them. Again, many of these women, as was learnt during the focus group discussion are from homes where they are not encouraged to obtain information or even access to people who could direct them to join support groups. Thus, the lack of family support in form of provision of adequate and proper care robs them of access to approved health services. In some situations they are completely ignorant about proper services related to HIV/AIDS management.

During the Key Informant Interview session one respondent observed that the failure of family support in the form of care giving is responsible for the late diagnosis and earlier management of HIV/AIDS victims. Another respondent stressed that care giving by the family instills self-confidence and it is a form of emotion booster. Care giving is seen as primary family support function.

To support the findings, Maldonado et al[34] found that verbal spoken expression such as mutual discussion and empathy by family members can positively (or negatively) affect women with HIV/AIDS. They stressed that when family members openly talk positively about women living with HIV/AIDS or communicate or socially interact well, the effect is always pleasant. This reinforces feelings of acceptance by family members.

The findings of $\mathrm{Li}$ et al [35] have been supported by this study. These researchers discovered that positive family communication and support contribute to overcome side effects and reinvigorates a stable routine live and motivation to stay healthy. Therefore effective communication in the family enables women living with HIV/AIDS to feel socially accepted and this psychologically buoys up their spirits.

Furthermore, our findings are consistent with the 
discovery by Mosack and Petroll that effective communication within the family is necessary as a process of enabling family members living with HIV/AIDS respond to the symbolic behavior of other family members [36]. Their findings stressed that the family plays a major role in ensuring that women living with HIV/AIDS are exposed to information. Both improved information communication and development of stronger relationships would improve Family health and this could directly or indirectly correlate to major treatment outcome. This information or communication is seen as both the process and behavioral interaction of family members. The ability of family members to communicate clearly and accurately with women living with HIV/AIDS is one of the most valued family roles.

The findings further agree that effective communication by the family positively affects women living with HIV/AIDS while poor communication irritates HIV/AIDS victims and reinforces stigmatization [37]. This may affect the women access to health services and their efforts to help them cope with the problems. Therefore proper and effective communication would strengthen their belief that they could survive after all.

The result of the focus group discussion also strongly agrees with the findings of this hypothesis. The discussants in the two session agreed that exposing women living with HIV/AIDS to proper information is an essential element of the other family members. It is an essential means through which meaningful social interaction occurs and helps to integrate women living with HIV/AIDS with their real family, community and the society.

The in-depth interview session revealed that allowing women living with HIV/AIDS access to information concerning when and where to obtain assistance, counseling or help in their predicament facilitates longer living and enables them cope with their situation. Many of those interviewed asserted that communication served a vital link between the family and women living with HIV/AIDS.

\section{Conclusion}

Based on our findings, it is concluded that there is a significant relationship between favourable social attitude and coping strategy of women living with HIV/AIDS. The better the social attitude the more the women living with HIV/AIDS will cope with the burden of the disease.

Care giving significantly relates to coping strategy of women living with HIV/AIDS. The more the family devotes attention to care giving, the better the healthy-living, care and love that will be promoted.

Significant relationship exists between effective communication (exposure to information) and coping strategy of women living with HIV/AIDS. Exposures to information enhance social interaction and enable women cope successfully in this period of their lives.

The coping strategies of women living with HIV/AIDS are significantly enhanced through developing favourable social attitude, involving proper and adequate care giving, effective and proper communication (exposure to information).

\section{Recommendations}

The following recommendations are made:

- That the family should show itself as the most fundamental institution for the successful management of HIV/AIDS.

- That the social attitude of the family should be geared towards ensuring the healthy living of victims of HIV/AIDS. Therefore social attitude that enhances stigmatization and discrimination should be discouraged.

- The family should show more love, affection and care to women living with HIV/AIDS to enable them feel part of the unit that they once totally belonged.

- Women living with HIV/AIDS should always have access to information to enable them make use of counseling and medical services.

- Women living with HIV should be empowered by the government. This can be in the form of employment, skill acquisition, access to loan, free medical services, to mention a few.

\section{Suggestions}

This study did not include representation of other religious groups apart from Christianity. This is because this study took place in south-southern part of Nigeria, occupied predominantly by Christians. It is suggested that another study should be carried out to involve study populations from different religions since this plays a role in family social attitude.

\section{References}

[1] Famoroti TO, Fernandez L, Chima S. stigmatization of people living with HIV/AIDS by health workers at a tertiary hospital in Kwazulu-Natal, South Africa: a cross sectional descriptive study. BMC Med Ethics 2013;14 (Suppl 1):56

[2] Aberg JA. Women and HIV: an overview. Accessed from ww.prn.org on the 4 th of July 2014

[3] Adeokun L.Social and cultural factors affecting HIV epidemic. In Olusoji A, Kanki PF (ed). AIDS in Nigeria. Cambridge Havard Centre for population and development studies 2006; 349-384

[4] Ndams IS, Joshua IA, Aluka SA, Sadiq HO, Ayodele SB. Human immunodeficiency virus sero-prevalence among pregnant women in Minna Nigeria. Ann Nigerian Med 2010;4:14-17

[5] Popoola RO. Beyond women rights. IOSR Journal of Humanities and Social Science 2014;19(Issue 3):112-118

[6] UNAIDS Fact Sheet. 2014, UNAIDS, New York USA Accessed from www.unaids.org on the 24th of August 2014

[7] Report on the Global AIDS epidemic, UNAIDS 2013, New York, USA) Accessed from www.unaids.org on 24th August 2014) 
[8] Entonu PE, Agwale SM. A review of the epidemiology, prevention and treatment of Human immunodeficiency virus infection in Nigeria. Brazilian Journal of Infectious Disease 2007;11(6):579-590.

[9] Magowe MKM. The meaning, lived experiences and intention for safer sex communication among young Botswana women in dyadic relationship. Open Journal of Nursing 2012;2:262269

[10] Udonwa NE, Ekpo M, Ekanem IA, Inem VA, Etokidem A. Oil doom and AIDS boom in the Niger Delta Region of Nigeria. Rural and Remote Health 4 (online), 2004: 273. Available from: http://www.rrh.org.au

[11] Udonwa N. E, Gyuse A. N. Etokidem A., Ekanem I. A. HIV/AIDS, Women and Poverty: Socio-Cultural Imperatives in Oil-bearing communities in the Niger Delta Region of Nigeria. Mary Slessor Journal of Medicine (MSJM) 2008; 8 (1): 6-11

[12] Ramjee G, Daniels B. Women and HIV in Sub-Saharan Africa. AIDS Res Ther 2013;10:30

[13] Cockcroft A, Kunda JL, Kgakole L, Masisi M, Laetsang D, Ho-Foster A et al. community views of intergenerational sex: findings from focus groups in Botswana, Namibia and Swaziland. Psychol Health Med 2010;15(5):507-514.

[14] Robinson, J, Yeh E. "Transactional Sex as a Response to Risk in Western Kenya." American Economic Journal: Applied Economics, 2011; 3(1): 35-64.

[15] Muula AS. HIV infection and AIDS among young women in South Africa. Croat Med J2008;49(3):423-435

[16] Klot JF, Auerbach ID, Berry MR. Sexual violence and HIV transmission: survey of proceedings of scientific research planning meeting. Am J Reproductive Immunology 2013;69(01):5-9.

[17] IIiyasu Z, Isa S, Abubakar I, Babashani M, Galadanaiit. Domestic Violence among women living with HIV/AIDS in Kano Northern Nigeria. Afr J Reproductive Health 2011; 15[3]:41-49

[18] Kohli R, Purohit V, Karve L, Bhalera V, Karvand S, Sheela R. Caring for caregivers of people living with HIV in the family: A response to the HIV pandemic from two urban slum communities inpunei India plos one 2012: 7(9):e44989

[19] Schatz E, Mudha MS, William J. Female headed households contending with AIDS-related hardship in rural Africa. Heath place 2011;17(2):598-605

[20] Odhiambo C. HIV/AIDS and women in Africa International. Journal of Humanities and Social Sciences 2012;2(2):178-191.

[21] Nguyen TP, Oosterhoff Y, Ngoc PN, Hardon A. Self-help groups can improve utilization of post natal care by HIV infected mothers. Journal of the Assoc of Nurses in AIDS Care 2009;20(2):141-152.

[22] Canadian AIDS Society. Women HIV/AIDS support issues. Accessed from www.cdnaids.ca on the 5th of July 2014.
[23] Nasidi A, Harry T. O. The epidemiology of HIV/AIDS in Nigeria, Paperback edition 2006, pages 17-35

[24] Sarah Larsson, Sara Bodiless, A discipline study of selfperceived attitude regarding HIV/AIDS in cam body accessed from. www.diva-portal.org on the 5th of August 2014.

[25] Mordi D. Action fighter who never says die. Action News 2007:3(1) j 1-4.

[26] HenrikeKorner. Experience of Cald women living with HIV:children and parenting.HIV Australia 2012; 9(4):18

[27] Li L, Wa S, Wu Z, Sun S, Cui H, Jia M. Understanding family support for people living with HIV/AIDS in Yunnan, China Aids Behaviour, 2006; 10(5): 509-517.

[28] Caritas. Kenya, A charity helping children worldwide Accessed from www.caritas.us on the 4th of August 2014

[29] Clow B .Prevention care and support do not address the needs of girls and women. Accessed from www.cwhn.caon the 23rd of July 2014.

[30] Nyamathi AI, Thomas B,Greengold B, Swaminathan S. Perceptions and health care heeds of HIV positive Mothers in india.ProgCommunity partnership 2009, 3(2):99-108

[31] Pepijn van Empelen. What is the impact of HIV on families? Copenhagen, WHO Regional Office for Europe (Health Evidence Network report; http://www.euro.who.int/Document/E87762.pdf, December 2005. Accessed on the 3rd September. 2014from www.euro.who.int/_data/assets/pdf_file/0009/74664/E87762 .pdf

[32] NYSC Reproductive Health \& HIV/AIDS Prevention Project (2003).Manual for Peer educators, UNICEF.

[33] Kohli R,Purobit V, Karvet L,Bhalerao V, Karvande S, Rangan $S$ et al. Caring for caregivers of people living with HIV in the Family. A response to the HIV pandemic from two urban slum communities in Puro India. Plos One 2012;7(9)e44989.

[34] Maldonado J ,Gore-Felton C, Durán R,Diamond S, Koopman C, Spiegel DSupportive-Expressive Group Therapy for People with HIV Infection: A Primer, Psychosocial Treatment Laboratory, Stanford University School of Medicine, Stanford, $\mathrm{Ca}, 1996$

[35] Li L, Lee S J, Wen Y, Lin C, Wan D, Jiraphongsa C. Antiretroviral therapy adherence among patients living with HIV/AIDS in Thailand. Nur Health Sc 2010:12(2):212 - 220.

[36] Mosack KE, Petrol A. Patients' perspectives on informal caregiver involvement in HIV health care appointments.AIDS Patient Care STDS, 2009 Dec; 23(12): 1043-51. doi: 10.1089/apc. 2009.0020

[37] Adeokun L, Okonkwo P, Ladipo O. The stigmatization of people living with HIV/AIDS in: AdeniyiO, Kanki P., Odutolu O, Idoku J (Eds) 2006. AIDS in Nigeria: A nation on the threshold Cambridge: Harvard University Press 213-233. 